\title{
Luminescence Properties of $\mathrm{CaF}_{2}$ Nanostructure Activated by Different Elements
}

\author{
Numan Salah, ${ }^{1}$ Najlaa D. Alharbi, ${ }^{2}$ Sami S. Habib, ${ }^{3}$ and S. P. Lochab ${ }^{4}$ \\ ${ }^{1}$ Center of Nanotechnology, King Abdulaziz University, Jeddah 21589, Saudi Arabia \\ ${ }^{2}$ Sciences Faculty for Girls, King Abdulaziz University, Jeddah 21589, Saudi Arabia \\ ${ }^{3}$ Department of Aeronautical Engineering, King Abdulaziz University, Jeddah 21589, Saudi Arabia \\ ${ }^{4}$ Inter-University Accelerator Centre, Aruna Asaf Ali Marg, New Delhi 110067, India
}

Correspondence should be addressed to Numan Salah; nsalah@kau.edu.sa

Received 29 September 2014; Accepted 9 December 2014

Academic Editor: Songjun Zeng

Copyright (C) 2015 Numan Salah et al. This is an open access article distributed under the Creative Commons Attribution License, which permits unrestricted use, distribution, and reproduction in any medium, provided the original work is properly cited.

\begin{abstract}
Nanostructures of calcium fluoride $\left(\mathrm{CaF}_{2}\right)$ doped with $\mathrm{Eu}, \mathrm{Tb}, \mathrm{Dy}, \mathrm{Cu}$, and $\mathrm{Ag}$ were synthesized by the coprecipitation method and studied for their thermoluminescence (TL) and photoluminescence (PL) properties. The PL emission spectrum of pure $\mathrm{CaF}_{2}$ nanostructure has a broad band in the $370-550 \mathrm{~nm}$ range. Similar spectra were observed in case of doped samples, beside extra bands related to these impurities. The maximum PL intensity was observed in Eu doped sample. The TL results of Eu, $\mathrm{Cu}, \mathrm{Ag}$, and $\mathrm{Tb}$ doped samples show weak glow peaks below $125^{\circ} \mathrm{C}$, whereas Dy doped one is found to be highly sensitive with a prominent peak at $165^{\circ} \mathrm{C}$. This sample was further exposed to a wide range of gamma rays exposures from ${ }^{137} \mathrm{Cs}$ source. The response curve is linear in the $100 \mathrm{~Gy}-10 \mathrm{kGy}$ range. It is also observed that the particle size of $\mathrm{CaF}_{2}$ nanostructure was significantly reduced by increasing Dy concentration. These results showed that $\mathrm{Dy}$ is a proper activator in the host of $\mathrm{CaF}_{2}$ nanostructure, providing a highly sensitive dosimeter in a wide range of exposures and also plays a role as a controlling agent for particle size growth.
\end{abstract}

\section{Introduction}

Nanoscale materials or nanostructures have attracted huge attention in the last two decades due to their unique properties. They have a potential to be used in a variety of applications. A large number of individuals and research groups from different fields have produced different nanomaterials and studied their properties. These include structural, optical, electrical, magnetic, mechanical, and dosimetric properties [1-5]. Many methods of preparations have also been developed in the last two decades, where different nanostructures like nanoparticles, nanocubes, nanowires, nanorods, and so forth, of several materials have been produced [6, 7]. Recent investigations have showed that the optical, luminescent, and other properties can be modified by the shape and size of the nanostructures. The role of impurity(ies) in the host of these nanostructure is another parameter that can be used to modify their properties [8-10].
Thermoluminescence (TL) is a well-known technique widely used for detection and measurement of absorbed radiation and dating of archaeological samples. It is a powerful technique for detecting defects in solid materials and dosimetry of different ionizing radiations. The presently used TL dosimeter (TLD) materials are inorganic crystalline materials mainly low $Z$ effective compounds. However, the selected TLD materials have advantage and drawbacks; therefore, efforts are still going on to improve their dosimetric properties. These improvements were tried to be achieved by either improving the TL characteristics of these TLD materials by preparing them using different methods or by doping with different impurities [11, 12]. Almost all of these phosphors have "dose ranges" depending on their "TL sensitivity" and "response characteristics" (linearity and saturation) to high energy radiations.

In the last few years, Salah and his group have produced nanostructures of some highly sensitive phosphors [13-21] 
and studied their TL response to different ionizing radiations. They observed that these nanostructures have unique dosimetric properties, mainly their linear response over a wide range of exposures along with a negligible fading. These nanomaterials are insensitive to heat treatments, making them quite useful to estimate the heavy doses of ionizing radiations. These results are observed in tissue and nontissue equivalent nanomaterials [13-21]. Other workers have also participated in testing TL response of some nanostructure materials to different ionizing radiations [22-28]. These studies showed that the TL response of these nanomaterials to ionizing radiations is mostly linear in a wide range of exposures; however, few studies were focused on the TL response of low $Z$ effective nanomaterials.

Calcium fluoride $\left(\mathrm{CaF}_{2}\right)$ is a wide band gap material with a large-scale transparency. Therefore, color center formation is possible just by irradiating $\mathrm{CaF}_{2}$ by ionizing radiation [29]. The material has a relatively low $Z$ effective, making it suitable for ionizing radiations used in radiotherapy. It was reported that this material is suitable as a laser material particularly, when doped with rare earth elements [30]. The nanostructure form of $\mathrm{CaF}_{2}$ was synthesized by different methods [29, 3133]. However, the TL and PL properties of this nanomaterial have not been well studied. Few studies were focused on the effect of different dopants on its optical properties [34-36]. Other investigations were focused on different routes for the syntheses of $\mathrm{CaF}_{2}$ nanocrystals and study of the upconversion luminescence by doping with some rare earths [37, 38]. In this work $\mathrm{CaF}_{2}$ nanostructure particles were doped with different impurities and studied for their TL response to gamma rays in a wide range of exposures. The effect of dopant concentration on the particle shape and size of $\mathrm{CaF}_{2}$ was also investigated (i.e., Dy in $\mathrm{CaF}_{2}$ nanocubes). Pure and doped samples were synthesized by the coprecipitation method. They were doped with Eu, Tb, Dy, Cu, and Ag. The as synthesized nanomaterials were characterized by XRD, SEM, DSC, and PL. Then they were exposed to a wide range of gamma rays exposures.

\section{Experimental}

Pure, europium (Eu), dysprosium (Dy), terbium (Tb), silver (Ag) and copper $(\mathrm{Cu})$ doped $\mathrm{CaF}_{2}$ nanocrystalline samples were synthesized by the chemical coprecipitation method. The samples of $\mathrm{CaF}_{2}$ were synthesized by using water and ethanol as solvents at a ratio of $1: 1$. The desired concentration of calcium chloride $\left(\mathrm{CaCl}_{2}\right)$ was dissolved in triply distilled DI water. The normality of the solution was kept at $0.2 \mathrm{~N}$. This solution was mixed with ammonium fluoride $\left(\mathrm{NH}_{4} \mathrm{~F}\right)$ solution (has a normality of $0.2 \mathrm{~N}$ ). The solution of ammonium fluoride was added to that of calcium chloride dropwise with continuous stirring. The formed precipitate was filtered out and washed with distilled water several times. The resulting powder samples, thus obtained, were dried at $70^{\circ} \mathrm{C}$ in an oven for 3 hours. The used chemicals in this experiment are highly pure and were of AR grade. The dopants used in this study were incorporated in their chloride forms except that of Ag dopant, where nitrate compound is used. A typical concentration of these impurities, that is, 0.2 mole $\%$, is used in $\mathrm{CaF}_{2}$ samples except those doped with Dy, where different concentrations in the range $0.05-2$ mole $\%$ are studied. In a typical case the desired concentration of the impurity, that is, $\mathrm{DyCl}_{3} \cdot 6 \mathrm{H}_{2} \mathrm{O}$, was added to the solution of $\mathrm{CaCl}_{2}$ and stirred for one hour before adding the solution of $\mathrm{NH}_{4} \mathrm{~F}$ as mentioned above. For TL study the produced samples were annealed at $350^{\circ} \mathrm{C}$ for $1 \mathrm{~h}$.

The samples of $\mathrm{CaF}_{2}$ were characterized by $\mathrm{X}$-ray diffraction (XRD), using an Ultima-IV (Rigaku, Japan) diffractometer with $\mathrm{Cu} \mathrm{K} \alpha$ radiation, while the morphology of these samples was studied by a field emission scanning electron microscopy (FESEM), JSM-7500 F (JEOL, Japan). Photoluminescence (PL) emission spectra were recorded at an excitation wavelength of $325 \mathrm{~nm}$ using a fluorescence spectrofluorophotometer, model RF-5301 PC, Shimadzu, Japan. A cutoff filter (UV-39) is used to block the emissions from the excitation source or scattered light. The PL measurement was conducted at room temperature. The study of temperature behavior was studied under nonisothermal measurements by using a Shimadzu DSC-60 instrument. Typically, $5 \mathrm{mg}$ of sample in powder form was sealed in standard aluminum sample pans and heated at heating rate of $10^{\circ} \mathrm{C} / \mathrm{min}$. The temperature precision of this equipment is $\pm 0.1 \mathrm{~K}$. Thermoluminescence (TL) glow curves were recorded on a Harshaw TLD reader (model 3500) under nitrogen atmosphere at a heating rate of $5^{\circ} \mathrm{C} / \mathrm{s}$. Neutral density filters of optimized density were used to avoid saturation of the photomultiplier tube (PMT) detector. For TL measurement $5 \mathrm{mg}$ of sample was taken each time. The background reading is initially recorded and subtracted from the samples reading.

\section{Results and Discussion}

Figure 1 shows SEM images at different magnifications ((a) and (b)) of pure $\mathrm{CaF}_{2}$ sample. These images show a mixture of spherical and cubic shape structures. These structures have sizes in the range of $20-80 \mathrm{~nm}$. The produced nanostructures have a good particle size distribution. As mentioned in Section 2 that the used compounds of $\mathrm{CaCl}_{2}$ and $\mathrm{NH}_{4} \mathrm{~F}$ were dissolved in water: ethanol mixture at a ratio of $1: 1$. This ratio was found to provide small nanostructures, while other ratios showed bigger particles.

Figure 2 shows XRD pattern of the as-synthesized pure $\mathrm{CaF}_{2}$ sample. Several diffracted peaks can be seen with hkl values indicating a complete crystalline structure in a cubic phase (JCPDS Card number 87-0971). The displayed peaks correspond to values ( $\left.\begin{array}{lll}1 & 1 & 1\end{array}\right),\left(\begin{array}{lll}2 & 2 & 0\end{array}\right),\left(\begin{array}{lll}3 & 1 & 1\end{array}\right)$, and ( $\left.\begin{array}{lll}4 & 0 & 0\end{array}\right)$. The XRD pattern presents broad peaks revealing the small crystallite size of the synthesized samples. This result is similar to that reported in the literature [29]. The nanocrystalline size was calculated using Scherer's formula and found to be around $35 \mathrm{~nm}$. This value is close to that observed by SEM (Figure 2). XRD of the doped samples was also studied, but the result is similar to that of pure $\mathrm{CaF}_{2}$ nanostructure. The concentration of these dopants used in this study was low, which is 0.2 mole $\%$. At this concentration 


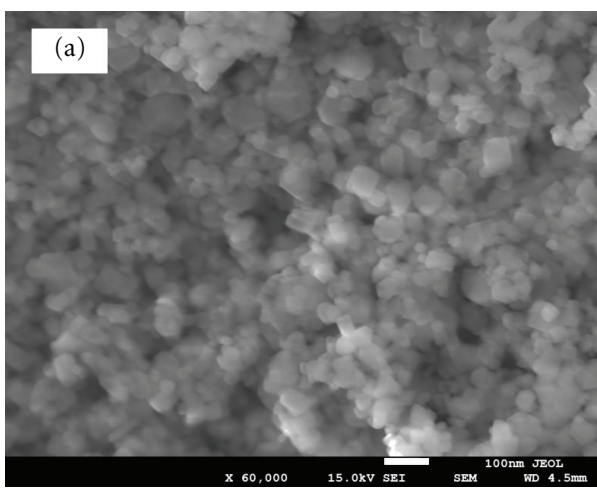

(a)

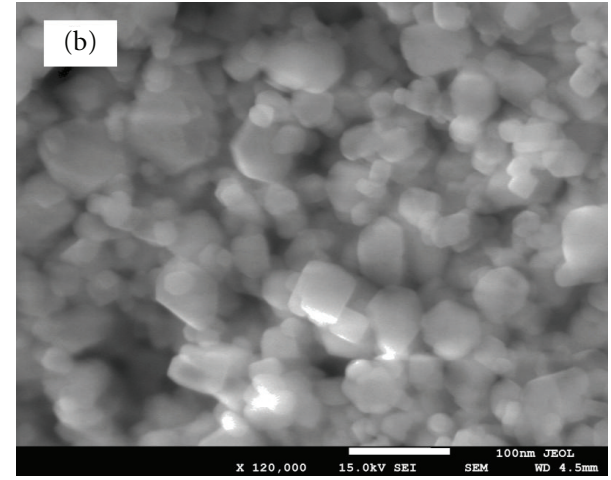

(b)

FIGURE 1: SEM images of the as-synthesized $\mathrm{CaF}_{2}$ nanostructures taken at different magnifications.

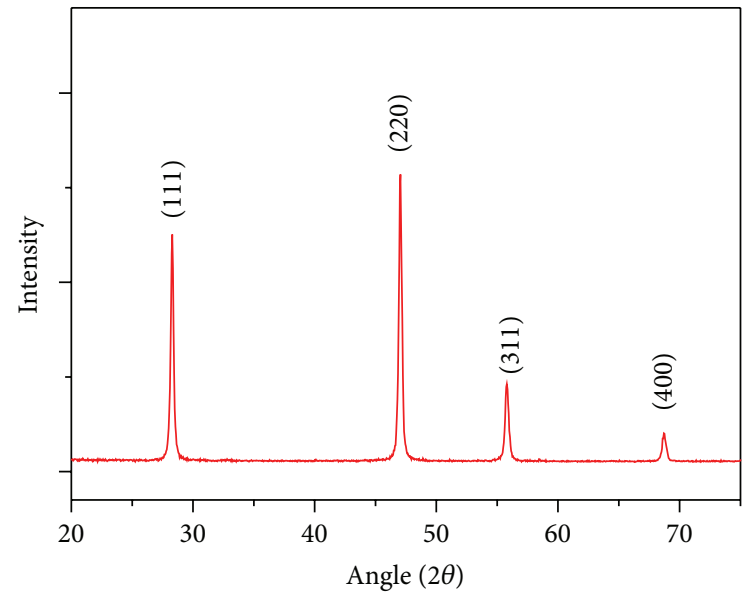

FIGURE 2: XRD pattern of the as-synthesized $\mathrm{CaF}_{2}$ nanostructures.

no significant changes are observed in the XRD peak of pure sample.

DSC measurement for pure $\mathrm{CaF}_{2}$ sample was conducted in the range of $30-600^{\circ} \mathrm{C}$. The DSC curve is shown in Figure 3. There is no endo- or exothermic peaks in this range, which means that pure $\mathrm{CaF}_{2}$ has only a single phase. For the dosimetry using thermoluminescence technique, the material of the dosimeter should be thermally stable without any phase transitions in the range $40-400^{\circ} \mathrm{C}$.

Figure 4 shows the PL emission spectra of the asproduced nanostructures of pure (curve (a)) and doped $\mathrm{CaF}_{2}$ samples (curves (b)-(f)). As mentioned above, the samples of $\mathrm{CaF}_{2}$ nanostructures were doped with $\mathrm{Ag}, \mathrm{Eu}, \mathrm{Tb}, \mathrm{Cu}$, and $\mathrm{Dy}$ at a concentration of $0.2 \mathrm{~mole} \%$ and their PL result is shown in curves (b), (c), (d), (e), and (f), respectively. Pure sample (curve (a)) shows a broad band in the $370-550 \mathrm{~nm}$ range. This band might be induced due to the formation of color centers. These centers perhaps could be created by oxygen defects within the host of $\mathrm{CaF}_{2}$. It has been reported [39] that oxygen defects (contaminations) can induce such emission bands, but at the higher wavelength side of the visible region. In the present $\mathrm{CaF}_{2}$ nanostructures, reducing the particle size

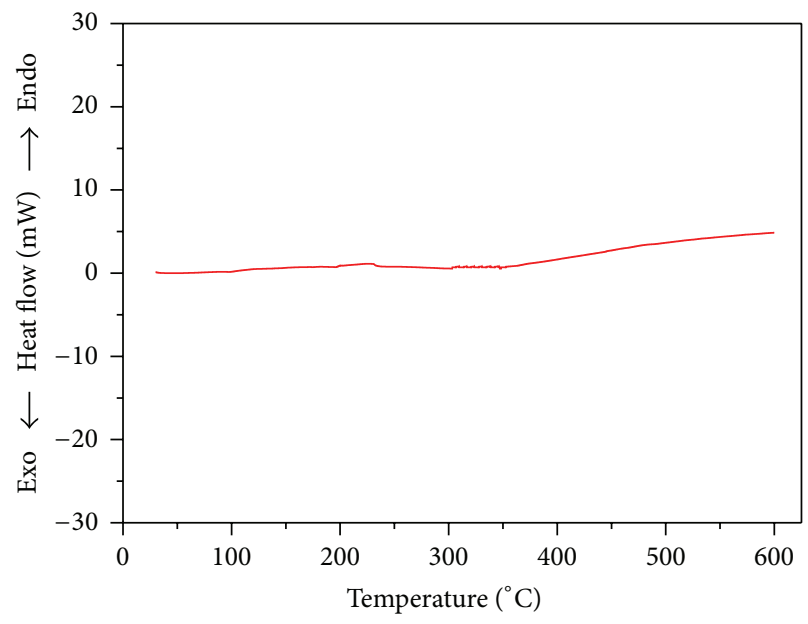

FIGURE 3: DSC plot for the as-synthesized $\mathrm{CaF}_{2}$ nanostructures.

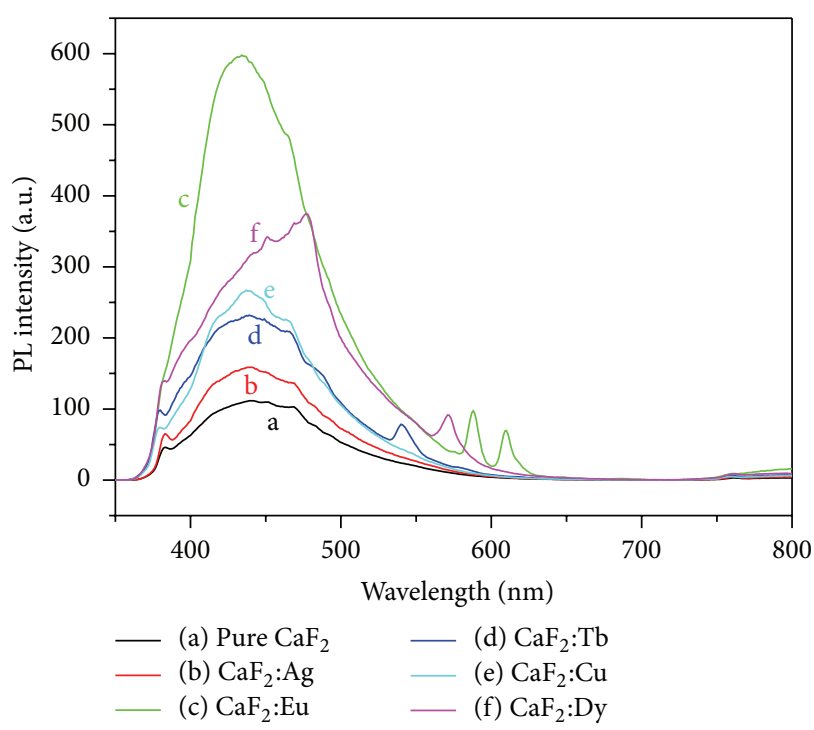

FIGURE 4: PL emission spectra of the as-synthesized nanostructures of pure and doped $\mathrm{CaF}_{2}$ samples, doped with different impurities at a concentration of 0.2 mole $\%$. 
to the nanoscale possibly could shift the emission bands to the lower wavelength, which might be due to a widening induced in the band gap of the material.

The PL emission spectra of $\mathrm{Ag}, \mathrm{Tb}$, and $\mathrm{Cu}$ doped samples shown in Figure 4 (curves (b), (d), and (e)) are almost similar to that of pure $\mathrm{CaF}_{2}$ (curve (a)), but with a slight PL enhancement. The observed enhancement in case of Ag doped sample might be due to the increase in absorption and quantum yield. This absorption perhaps could be increased due to the surface plasmon resonance of $\mathrm{Ag}$ ions [40]. $\mathrm{Ag}$ dopants could perhaps be incorporated in metallic form [41]. It is also possible that some of these dopants could form small clusters; however, this is a preliminary speculation and further investigations are needed to prove the actual nature of $\mathrm{Ag}$ as a dopant in $\mathrm{CaF}_{2}$ host.

The emission spectrum of $\mathrm{Tb}$ doped sample shows extra band at $544 \mathrm{~nm}$. This band is the well-known emission of $\mathrm{Tb}^{3+}$ ion, which can be assigned to the ${ }^{5} \mathrm{D}_{4} \rightarrow{ }^{7} \mathrm{~F}_{6}$ transition of $\mathrm{Tb}^{3+}$ ion [42]. In case of copper $(\mathrm{Cu})$ ion it is possible that it might get incorporated in the host of $\mathrm{LiF}$ matrix in its $2+$ form $\left(\mathrm{Cu}^{2+}\right)$. This ion mostly shows its emission in the visible region. This ion was reported by several authors to have emission bands in the 400-500 region [43, 44]; therefore, the broad band at $370-550 \mathrm{~nm}$ might include the emission of $\mathrm{Cu}^{2+}$ and thus showed PL enhancement.

The PL emission spectra of Eu and Dy doped samples (Figure 4, curves (c) and (f)) show strong enhancement in intensity of the broad band at $370-550 \mathrm{~nm}$, with the emergence of extra sharp emissions. The broad band at 370$550 \mathrm{~nm}$ has the highest PL intensity in Eu doped sample. This is in association with emergence of two bands located at 590 and $615 \mathrm{~nm}$, which are the well-known emissions of $\mathrm{Eu}^{3+}$ ion [45]. Dy ion might get introduced into the host of $\mathrm{CaF}_{2}$ matrix in its $3+$ form $\left(\mathrm{Dy}^{3+}\right)$ and this ion is a wellknown activator mostly showing its emission in the visible region. This ion was reported by several authors to have two emissions at around 485 and $572 \mathrm{~nm}$ [46], which are close to the emission region of pure $\mathrm{CaF}_{2}$. The first emission of $\mathrm{Dy}^{3+}$ in $\mathrm{CaF}_{2}$ matrix probably could enhance the PL emission of pure sample by superimposing these emissions.

Figure 5 shows the TL glow curves of $\mathrm{CaF}_{2}$ nanostructures doped with different elements at a concentration of 0.2 mole\% (curves (a), (b), (c), (d), and (e)). These samples were exposed to $1 \mathrm{kGy}$ of ${ }^{137} \mathrm{Cs}$ gamma rays. The glow peaks of $\mathrm{Eu}, \mathrm{Cu}$, and $\mathrm{Ag}$ dopants (curves (a), (d), and (e)) are located at around $125^{\circ} \mathrm{C}$ with a version in their relative TL intensity. $\mathrm{Tb}$ doped $\mathrm{CaF}_{2}$ nanostructures (curve (c)) has stronger glow peak at lower temperature side, that is, around $95^{\circ} \mathrm{C}$. The Dy doped sample (curve (b)) shows a broad TL glow curve with a prominent peak at around $165^{\circ} \mathrm{C}$ along with smaller one at $135^{\circ} \mathrm{C}$. This curve has the highest TL intensity. This is a remarkable result to have a sensitive material with deeper traps, which is thermally stable with less fading. Moreover, Dy doped $\mathrm{CaF}_{2}$ sample seems to have a good population of electron traps, making it a good candidate to be tested for its response to heavy ions used in radiotherapy like carbon ions. The nanostructure form of $\mathrm{CaF}_{2}$ was tested by Zahedifar and Sadeghi $[34,47]$ and Zahedifar et al. [48] for its TL response

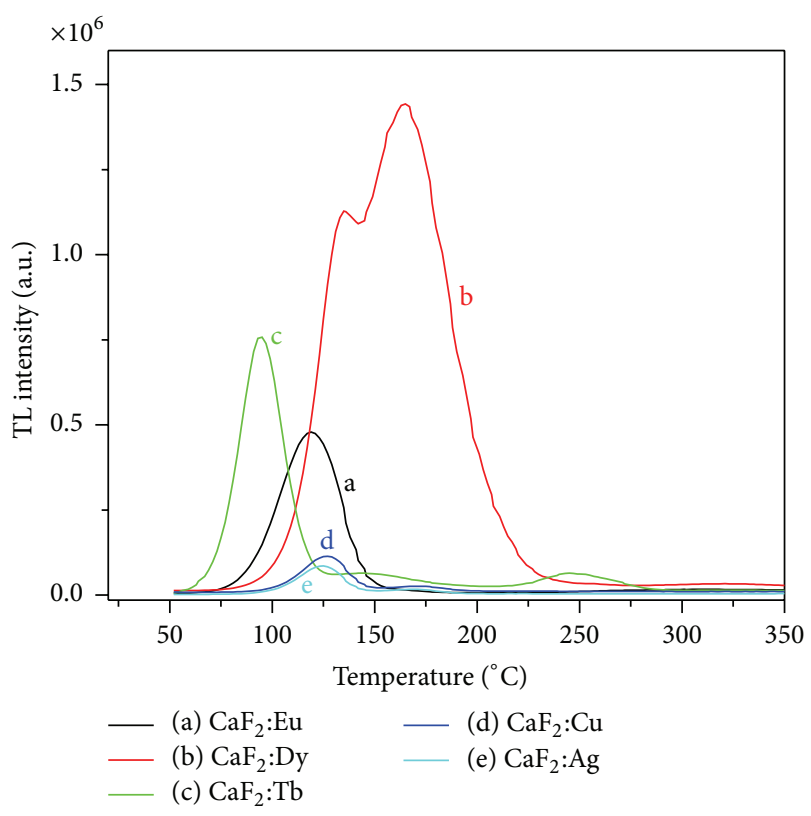

Figure 5: TL glow curves of $\mathrm{CaF}_{2}$ nanostructures doped with different elements and exposed to $1 \mathrm{kGy}$ of ${ }^{137} \mathrm{Cs}$ gamma rays.

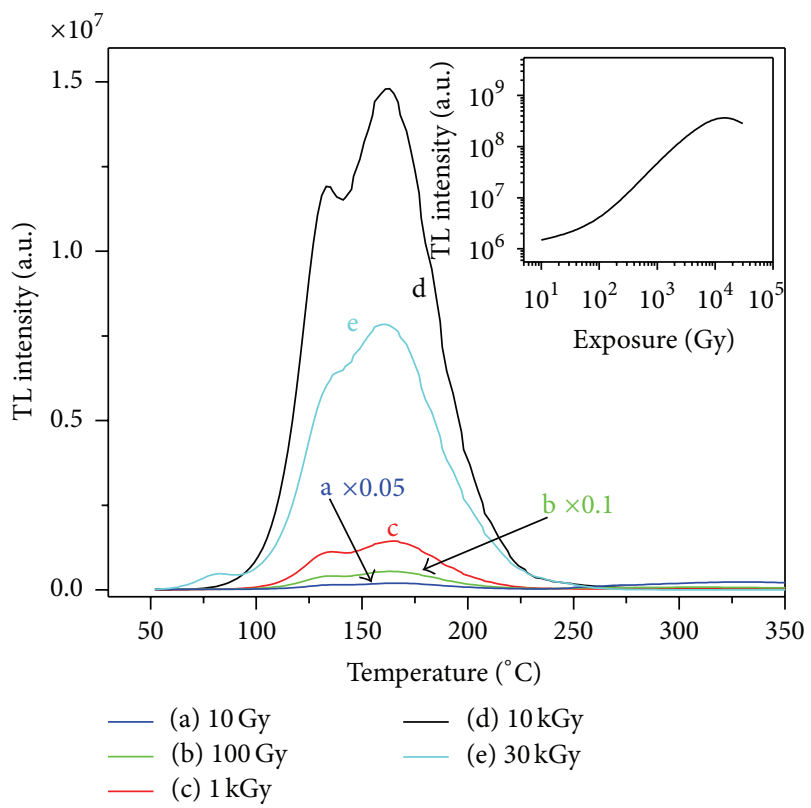

Figure 6: TL glow curves of $\mathrm{CaF}_{2}$ :Dy nanostructures exposed to different exposures of ${ }^{137} \mathrm{Cs}$ gamma rays. The figure in the inset is the corresponding TL response curve.

after doping with $\mathrm{Tm}, \mathrm{Ce}$. In their sample the permanent glow peak was observed at a relatively low temperature side, which is around $402 \mathrm{~K}\left(129^{\circ} \mathrm{C}\right)$. This makes $\mathrm{CaF}_{2}:$ Dy a superior due to its relatively high temperature glow peak. But it is quite useful to test the TL response of $\mathrm{CaF}_{2}$ :Dy nanostructures to different doses of gamma rays and observe the effect of different doses on the glow curve structure and peak position.

Figure 6 shows the TL glow curves of $\mathrm{CaF}_{2}$ :Dy nanostructures exposed to different exposures of ${ }^{137} \mathrm{Cs}$ gamma 


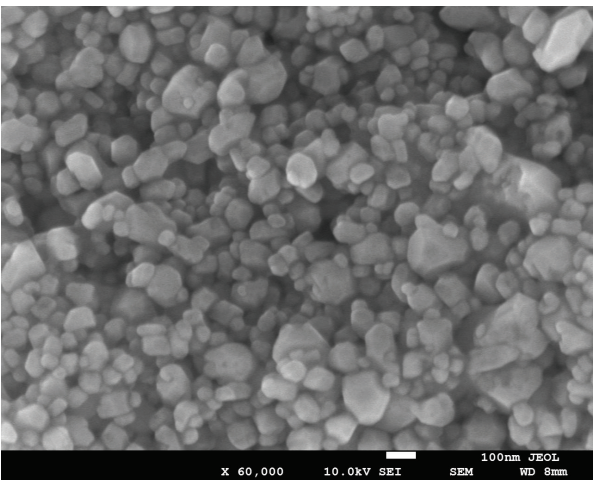

(a)

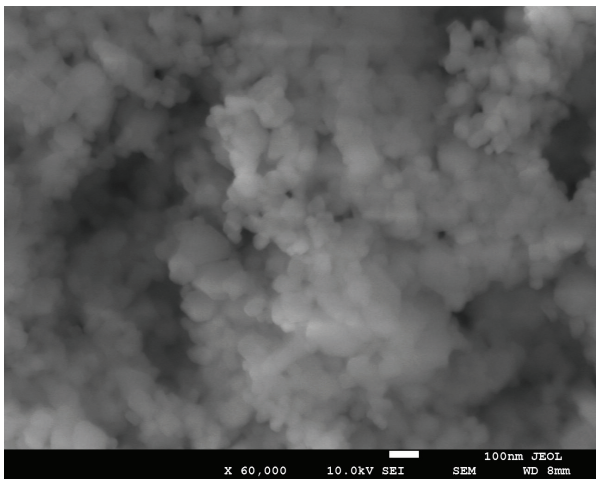

(c)

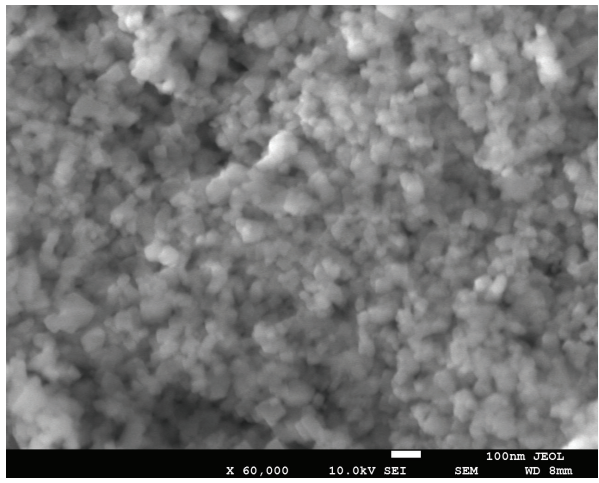

(e)

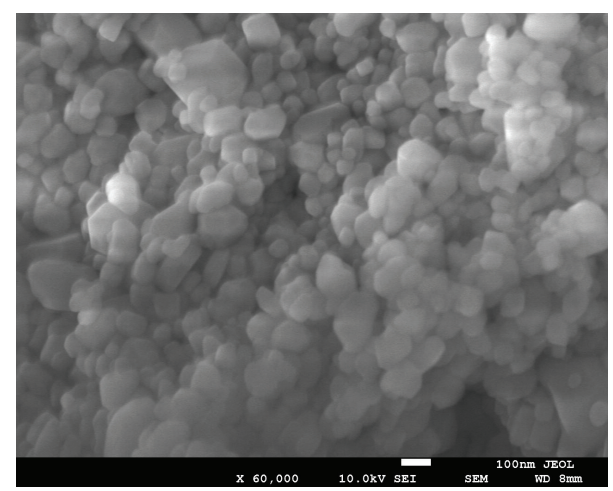

(b)

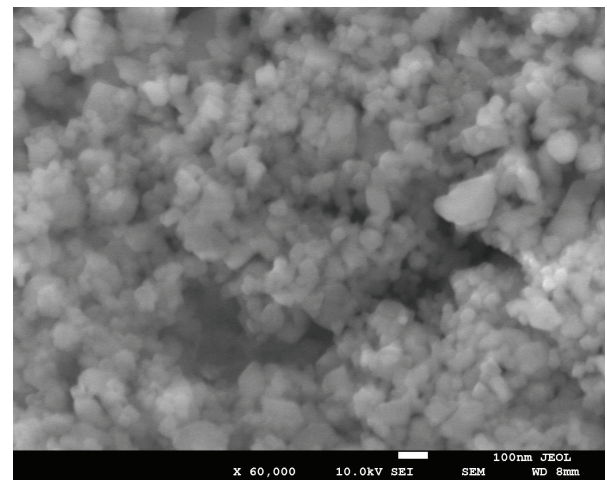

(d)

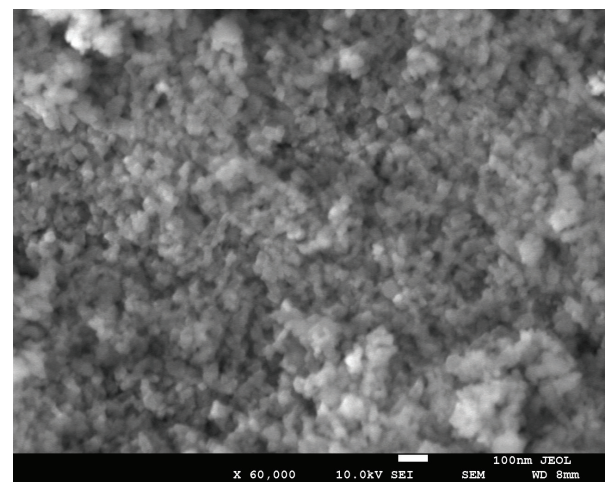

(f)

FIGURE 7: SEM images of (a) pure and Dy doped nanostructures of $\mathrm{CaF}_{2}$ sample ((b) 0.05, (c) 0.1, (d) 0.2, (e) 1 , and (f) 2 mole\%).

rays in the range of $10 \mathrm{~Gy}-30 \mathrm{kGy}$. There is no significant change in the glow curve structure or peak position. The intensity of the glow peaks increased by increasing the dose in the range $10 \mathrm{~Gy}-10 \mathrm{kGy}$ (curves (a), (b), (c), and (d)), but further exposure beyond this range results in decreasing the TL intensity of the glow peaks (curve (e)). Small TL glow peak emerged at around $70^{\circ} \mathrm{C}$ in case of $30 \mathrm{kGy}$ exposure, which might be due to the saturation of electrons at the existing electron traps resulting in creating shallow traps.

The TL response curve of $\mathrm{CaF}_{2}: \mathrm{Dy}$ nanostructures to different exposures of ${ }^{137} \mathrm{Cs}$ gamma rays was also plotted and presented in the inset of Figure 6. It shows that below
$100 \mathrm{~Gy}$ the curve is sublinear; then it is quite linear in the range of $100 \mathrm{~Gy}-10 \mathrm{kGy}$ and finally saturates (even decreases) beyond this range. The linear response in a wide range is good indicator for $\mathrm{CaF}_{2}$ :Dy nanocubes to be tested as a dosimeter for $\mathrm{C}$ ions. This wide response was explained earlier by Salah et al. $[13,49]$.

The effect of Dy concentration on the TL sensitivity of $\mathrm{CaF}_{2}$ nanostructures has been studied. Different concentrations within the range $0.05-2$ mole $\%$ were included in this study. The maximum TL sensitivity was found to be around $0.5 \mathrm{~mole} \%$. Strange result was also observed on the particle size of $\mathrm{CaF}_{2}$ nanostructures by changing Dy concentration. 
Figure 7 shows SEM images at the same magnifications for $\mathrm{CaF}_{2}$ nanostructures doped with Dy at different concentrations from 0.05 to 2 mole\% (images (a)-(f)). At low concentration (image (a)) the particle size is around $70-100 \mathrm{~nm}$. This size was significantly reduced to around $20 \mathrm{~nm}$ by increasing concentration of Dy to 2 mole\%. Similar results were also observed by Salah [50] on $\mathrm{Tb}$ doped $\mathrm{CaSO}_{4}$ nanorods. The reason for that was attributed to the well incorporation of rare earth ions in the host that could limit the growth of these nanostructures; this means that these rare earths ions could act as controlling agents for size growth. The other impurities perhaps could not be incorporated well neither interstitially nor substitutionally. Rare earths like $\mathrm{Dy}, \mathrm{Tb}$, and Eu have ionic radii close to that of $\mathrm{Ca}$, while those of $\mathrm{Ag}$ and $\mathrm{Cu}$ are different. Therefore, these rare earth ions perhaps could substitutionally be incorporated.

\section{Conclusion}

The TL and PL properties of $\mathrm{CaF}_{2}$ nanostructures doped with $\mathrm{Eu}, \mathrm{Tb}, \mathrm{Dy}, \mathrm{Cu}$, and Ag were studied. Thermally stable nanocrystalline materials with a single phase in the $30-600^{\circ} \mathrm{C}$ temperature range could be produced. The $\mathrm{PL}$ emission spectrum of pure $\mathrm{CaF}_{2}$ nanostructures has a broad band in the range of 370-550 $\mathrm{nm}$. The doped samples showed similar spectra in addition to extra bands related to these impurities. The maximum PL intensity was observed in Eu doped sample. Dy doped one was observed to be the most TL sensitive with a linear response curve in the $100 \mathrm{~Gy}-10 \mathrm{kGy}$ range. This impurity could also play a role as a controlling agent for particle size growth. These results showed that Dy is a proper activator in the host of $\mathrm{CaF}_{2}$ nanostructures, providing a highly sensitive dosimeter in a wide range of exposures that might be suitable for measurements of heavy doses.

\section{Conflict of Interests}

The authors declare that there is no conflict of interests regarding the publication of this paper.

\section{Acknowledgment}

Thanks are due to King Abdulaziz City for Science and Technology, Riyadh, Saudi Arabia, for providing financial assistance in the form of Research Project "A-T-32-72."

\section{References}

[1] B. Nasiri-Tabrizi and A. Fahami, "Mechanochemical synthesis and structural characterization of nano-sized amorphous tricalcium phosphate," Ceramics International, vol. 39, no. 8, pp. 8657-8666, 2013.

[2] S. P. Kim, D. U. Lee, and E. K. Kim, "Optical properties of metal-oxide nano-particles embedded in the polyimide layer for photovoltaic applications," Current Applied Physics, vol. 10, no. 3, supplement, pp. S478-S480, 2010.

[3] X. S. Lv, Z. H. Deng, F. X. Miao et al., "Fundamental optical and electrical properties of nano- $\mathrm{Cu}_{3} \mathrm{VS}_{4}$ thin film," Optical Materials, vol. 34, no. 8, pp. 1451-1454, 2012.
[4] P. Pulišová, J. Kováč, A. Voigt, and P. Raschman, "Structure and magnetic properties of Co and Ni nano-ferrites prepared by a two step direct microemulsions synthesis," Journal of Magnetism and Magnetic Materials, vol. 341, pp. 93-99, 2013.

[5] V. S. Kortov, "Nanophosphors and outlooks for their use in ionizing radiation detection," Radiation Measurements, vol. 45, no. 3-6, pp. 512-515, 2010.

[6] C. Wu, W. Qin, G. Qin et al., "Photoluminescence from surfactant-assembled $\mathrm{Y}_{2} \mathrm{O}_{3}$ :Eu nanotubes," Applied Physics Letters, vol. 82, no. 4, pp. 520-522, 2003.

[7] P. R. González, E. Cruz-Zaragoza, C. Furetta, J. Azorín, and B. C. Alcántara, "Effect of thermal treatment on TL response of $\mathrm{CaSO}_{4}$ :Dy obtained using a new preparation method," Applied Radiation and Isotopes, vol. 75, pp. 58-63, 2013.

[8] S. C. Qu, W. H. Zhou, F. Q. Liu et al., "Photoluminescence properties of $\mathrm{Eu}^{3+}$-doped $\mathrm{ZnS}$ nanocrystals prepared in a water/methanol solution," Applied Physics Letters, vol. 80, no. 19, article 3605, 2002.

[9] M. Isik, E. Bulur, and N. M. Gasanly, "TL and TSC studies on $\mathrm{TlGaSe}_{2}$ layered single crystals," Journal of Luminescence, vol. 144, pp. 163-168, 2013.

[10] A. Hernandez-Medina, A. Negron-Mendoza, S. Ramos-Bernal, and M. Colin-Garcia, "The effect of doses, irradiation temperature, and doped impurities in the thermoluminescence response of $\mathrm{NaCl}$ crystals," Radiation Measurements, vol. 56, pp. 369-373, 2013.

[11] J. I. Lee, I. Changa, J. L. Kim et al., "LiF:Mg,Cu,Si material with intense high-temperature TL peak prepared by various thermal treatment conditions," Radiation Measurements, vol. 46, no. 12, pp. 1496-1499, 2011.

[12] K. Tang, H. Cui, H. Zhu, Z. Liu, and H. Fan, "Newly developed highly sensitive $\mathrm{LiF}: \mathrm{Mg}, \mathrm{Cu}, \mathrm{Si}$ TL discs with good stability to heat treatment," Radiation Measurements, vol. 47, no. 2, pp. 185189, 2012.

[13] N. Salah, P. D. Sahare, and A. A. Rupasov, "Thermoluminescence of nanocrystalline LiF:Mg, Cu, P," Journal of Luminescence, vol. 124, no. 2, pp. 357-364, 2007.

[14] N. Salah, "Carbon ions irradiation on nano- and microcrystalline $\mathrm{CaSO}_{4}$ : Dy," Journal of Physics D: Applied Physics, vol. 41, no. 15, Article ID 155302, 2008.

[15] N. N. Salah, S. S. Habib, Z. H. Khan et al., "Nanorods of LiF: $\mathrm{Mg}, \mathrm{Cu}, \mathrm{P}$ as detectors for mixed field radiations," IEEE Transactions on Nanotechnology, vol. 7, no. 6, pp. 749-753, 2008.

[16] N. Salah, S. P. Lochab, D. Kanjilal et al., "Nanoparticles of $\mathrm{K}_{2} \mathrm{Ca}_{2}\left(\mathrm{SO}_{4}\right)_{3}$ :Eu as effective detectors for swift heavy ions," Journal of Applied Physics, vol. 102, no. 6, Article ID 064904, 2007.

[17] S. P. Lochab, D. Kanjilal, N. Salah et al., "Nanocrystalline $\mathrm{Ba}_{0.97} \mathrm{Ca}_{0.03} \mathrm{SO}_{4}$ :Eu for ion beams dosimetry," Journal of Applied Physics, vol. 104, no. 3, article 033520, 2008.

[18] N. Salah, S. S. Habib, Z. H. Khan, and S. P. Lochab, "The nanoparticles of $\mathrm{BaSO}_{4}: \mathrm{Eu}$ as detectors for high doses of different ionising radiations," Atoms for Peace, vol. 3, no. 2, p. 84, 2010.

[19] N. Salah, "Nanocrystalline materials for the dosimetry of heavy charged particles: a review," Radiation Physics and Chemistry, vol. 80, no. 1, pp. 1-10, 2011.

[20] N. Salah, S. Habib, S. S. Babkair, S. P. Lochab, and V. Chopra, "TL response of nanocrystalline $\mathrm{MgB}_{4} \mathrm{O}_{7}$ :Dy irradiated by $3 \mathrm{MeV}$

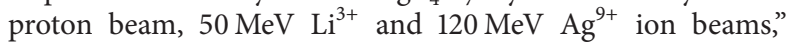
Radiation Physics and Chemistry, vol. 86, pp. 52-58, 2013. 
[21] N. Salah, N. D. Alharbi, and M. A. Enani, "Luminescence properties of pure and doped $\mathrm{CaSO}_{4}$ nanorods irradiated by $15 \mathrm{MeV}$ e-beam," Nuclear Instruments and Methods in Physics Research Section B: Beam Interactions with Materials and Atoms, vol. 319, pp. 107-111, 2014.

[22] V. Kumar, H. C. Swart, O. M. Ntwaeaborwa et al., "Thermoluminescence response of $\mathrm{CaS}: \mathrm{Bi}^{3+}$ nanophosphor exposed to 200 $\mathrm{MeV} \mathrm{Ag}{ }^{+15}$ ion beam," Optical Materials, vol. 32, no. 1, pp. 164$168,2009$.

[23] A. Pandey, S. Bahl, K. Sharm et al., "Thermoluminescence properties of nanocrystalline $\mathrm{K}_{2} \mathrm{Ca}_{2}\left(\mathrm{SO}_{4}\right)_{3}$ :Eu irradiated with gamma rays and proton beam," Nuclear Instruments and Methods in Physics Research B, vol. 269, no. 3, pp. 216-222, 2011.

[24] A. Choubey, S. K. Sharma, S. P. Lochab, and D. Kanjilal, "Excitation of thermoluminescence in Eu doped $\mathrm{Ba}_{0.12} \mathrm{Sr}_{0.88} \mathrm{SO}_{4}$ nanophosphor by low energy argon ions," Journal of Luminescence, vol. 131, no. 10, pp. 2093-2099, 2011.

[25] S. C. Prashantha, B. N. Lakshminarasappa, and F. Singh, "100 $\mathrm{MeV} \mathrm{Si}{ }^{8+}$ ion induced luminescence and thermoluminescence of nanocrystalline $\mathrm{Mg}_{2} \mathrm{SiO}_{4}: \mathrm{Eu}^{3+}$," Journal of Luminescence, vol. 132, no. 11, pp. 3093-3097, 2012.

[26] S. Bahl, A. Pandey, S. P. Lochab, V. E. Aleynikov, A. G. Molokanov, and P. Kumar, "Synthesis and thermoluminescence characteristics of gamma and proton irradiated nanocrystalline $\mathrm{MgB}_{4} \mathrm{O}_{7}$ : Dy, Na," Journal of Luminescence, vol. 134, pp. 691-698, 2013.

[27] C. Manjunatha, D. V. Sunitha, H. Nagabhushana et al., “Thermoluminescence properties of $100 \mathrm{MeV} \mathrm{Si}^{7+}$ swift heavy ions and UV irradiated $\mathrm{CdSiO}_{3}: \mathrm{Ce}^{3+}$ nanophosphor," Journal of Luminescence, vol. 134, pp. 358-368, 2013.

[28] D. V. Sunitha, H. Nagabhushana, and S. C. Sharma, "Structural, iono and thermoluminescence properties of heavy ion $\left(100 \mathrm{MeV} \mathrm{Si}^{7+}\right)$ bombarded $\mathrm{Zn}_{2} \mathrm{SiO}_{4}: \mathrm{Sm}^{3+}$ nanophosphor," Journal of Luminescence, vol. 143, pp. 409-417, 2013.

[29] C. Pandurangappa and B. Lakshminarasappa, "Optical absorption and Photoluminescence studies in Gamma-irradiated nanocrystalline CaF2," Journal of Nanomedicine and Nanotechnology, vol. 2, no. 2, 2011.

[30] V. Petit, J. L. Doualan, P. Camy, V. Ménard, and R. Moncorgé, " $\mathrm{CW}$ and tunable laser operation of $\mathrm{Yb}^{3+}$ doped $\mathrm{CaF}_{2}$," Applied Physics B, vol. 78, no. 6, pp. 681-684, 2004.

[31] G. A. Kumar, C. W. Chen, J. Ballato, and R. E. Riman, "Optical characterization of infrared emitting rare-earth-doped fluoride nanocrystals and their transparent nanocomposites," Chemistry of Materials, vol. 19, no. 6, pp. 1523-1528, 2007.

[32] A. Bensalah, M. Mortier, G. Patriarche, P. Gredin, and D. Vivien, "Synthesis and optical characterizations of undoped and rare-earth-doped $\mathrm{CaF}_{2}$ nanoparticles," Journal of Solid State Chemistry, vol. 179, no. 8, pp. 2636-2644, 2006.

[33] C. Cao, W. Qin, J. Zhang et al., "Up-conversion white light of $\mathrm{Tm}^{3+} / \mathrm{Er}^{3+} / \mathrm{Yb}^{3+}$ tri-doped $\mathrm{CaF}_{2}$ phosphors," Optics Communications, vol. 281, no. 6, pp. 1716-1719, 2008.

[34] M. Zahedifar and E. Sadeghi, "Synthesis and thermoluminescence properties of CaF2: Tm, Ce nanoparticles," Iranian Journal of Physics Research, vol. 13, no. 3, p. 55, 2013.

[35] D. Chen, Y. Wang, E. Ma, Y. Yu, and F. Liu, "Partition, luminescence and energy transfer of $\mathrm{Er}^{3+} / \mathrm{Yb}^{3+}$ ions in oxyfluoride glass ceramic containing $\mathrm{CaF}_{2}$ nano-crystals," Optical Materials, vol. 29, no. 12, pp. 1693-1699, 2007.

[36] C. Pandurangappa, B. N. Lakshminarasappa, and B. M. Nagabhushana, "Synthesis and optical studies of gamma irradiated Eu doped nanocrystalline $\mathrm{CaF}_{2}$," Journal of Alloys and Compounds, vol. 509, no. 29, pp. 7671-7673, 2011.

[37] J. Tao, Q. Weiping, and Z. Dan, "Size-dependent upconversion luminescence in $\mathrm{CaF}_{2}: \mathrm{Yb}^{3+}, \mathrm{Tm}^{3+}$ nanocrystals," Materials Letters, vol. 74, pp. 54-57, 2012.

[38] Y. Li, T. Liu, and Y. Du, "Accelerated fabrication and upconversion luminescence of $\mathrm{Yb}^{3+} / \mathrm{Er}^{3+}$-codoped $\mathrm{CaF}_{2}$ nanocrystal by microwave heating," Applied Physics Express, vol. 5, no. 8, Article ID 086501, 2012.

[39] F. Somma, R. M. Montereali, M. A. Vincenti, S. Polosan, and M. Secu, "Radiation induced defects in $\mathrm{Pb}^{+2}$-doped LiF crystals," Physics Procedia, vol. 2, no. 2, pp. 211-221, 2009.

[40] M. Darroudi, M. B. Ahmad, A. H. Abdullah, N. A. Ibrahim, and K. Shameli, "Effect of accelerator in green synthesis of silver nanoparticles," International Journal of Molecular Sciences, vol. 11, no. 10, pp. 3898-3905, 2010.

[41] Y. Chen, X. L. Xu, G. H. Zhang, H. Xue, and S. Y. Ma, "A comparative study of the microstructures and optical properties of $\mathrm{Cu}$ - and Ag-doped $\mathrm{ZnO}$ thin films," Physica B: Condensed Matter, vol. 404, no. 20, pp. 3645-3649, 2009.

[42] S. Sato, S. Kamei, K. Uematsu et al., "Synthesis and luminescence properties of rare earth doped $\mathrm{Na}_{3} \mathrm{AlP}_{3} \mathrm{O}_{9} \mathrm{~N}$ oxynitridophosphate phosphor," Journal of Ceramic Processing Research, vol. 14, no. 1, pp. s74-s76, 2013.

[43] W.-C. Lin, C.-Y. Wu, Z.-H. Liu, C.-Y. Lin, and Y.-P. Yen, "A new selective colorimetric and fluorescent sensor for $\mathrm{Hg}^{2+}$ and $\mathrm{Cu}^{2+}$ based on a thiourea featuring a pyrene unit," Talanta, vol. 81, no. 4-5, pp. 1209-1215, 2010.

[44] N. Li, Y. Xiang, and A. Tong, "Highly sensitive and selective "turn-on" fluorescent chemodosimeter for $\mathrm{Cu}^{2+}$ in water via $\mathrm{Cu}^{2+}$-promoted hydrolysis of lactone moiety in coumarin," Chemical Communications, vol. 46, no. 19, pp. 3363-3365, 2010.

[45] K. Sivaiah and S. Buddhudu, "Light-emission in $\mathrm{Tb}^{3+}$ and $\mathrm{Eu}^{3+}$ : PVP polymer films," Indian Journal of Pure and Applied Physics, vol. 49, no. 6, pp. 377-381, 2011.

[46] Y.-C. Li, Y.-H. Chang, Y.-F. Lin, Y.-S. Chang, and Y.-J. Lin, "Synthesis and luminescent properties of $\mathrm{Ln}^{3+}\left(\mathrm{Eu}^{3+}, \mathrm{Sm}^{3+}\right.$, $\mathrm{Dy}^{3+}$ )-doped lanthanum aluminum germanate $\mathrm{LaAlGe}_{2} \mathrm{O}_{7}$ phosphors," Journal of Alloys and Compounds, vol. 439, no. 1-2, pp. 367-375, 2007.

[47] M. Zahedifar and E. Sadeghi, "Synthesis and dosimetric properties of the novel thermoluminescent $\mathrm{CaF}_{2}: \mathrm{Tm}$ nanoparticles," Radiation Physics and Chemistry, vol. 81, no. 12, pp. 1856-1861, 2012.

[48] M. Zahedifar, E. Sadeghi, and Z. Mohebbi, "Synthesis and thermoluminescence characteristics of $\mathrm{Mn}$ doped $\mathrm{CaF}_{2}$ nanoparticles," Nuclear Instruments and Methods in Physics Research, Section B: Beam Interactions with Materials and Atoms, vol. 274, pp. 162-166, 2012.

[49] N. Salah, Z. H. Khan, and S. S. Habib, "Copper activated LiF nanorods as TLD material for high exposures of gamma-rays," Nuclear Instruments and Methods in Physics Research Section B: Beam Interactions with Materials and Atoms, vol. 267, no. 21-22, pp. 3562-3565, 2009.

[50] N. Salah, "Thermoluminesence of gamma rays irradiated $\mathrm{CaSO}_{4}$ nanorods doped with different elements," Radiation Physics and Chemistry, vol. 106, pp. 40-45, 2015. 

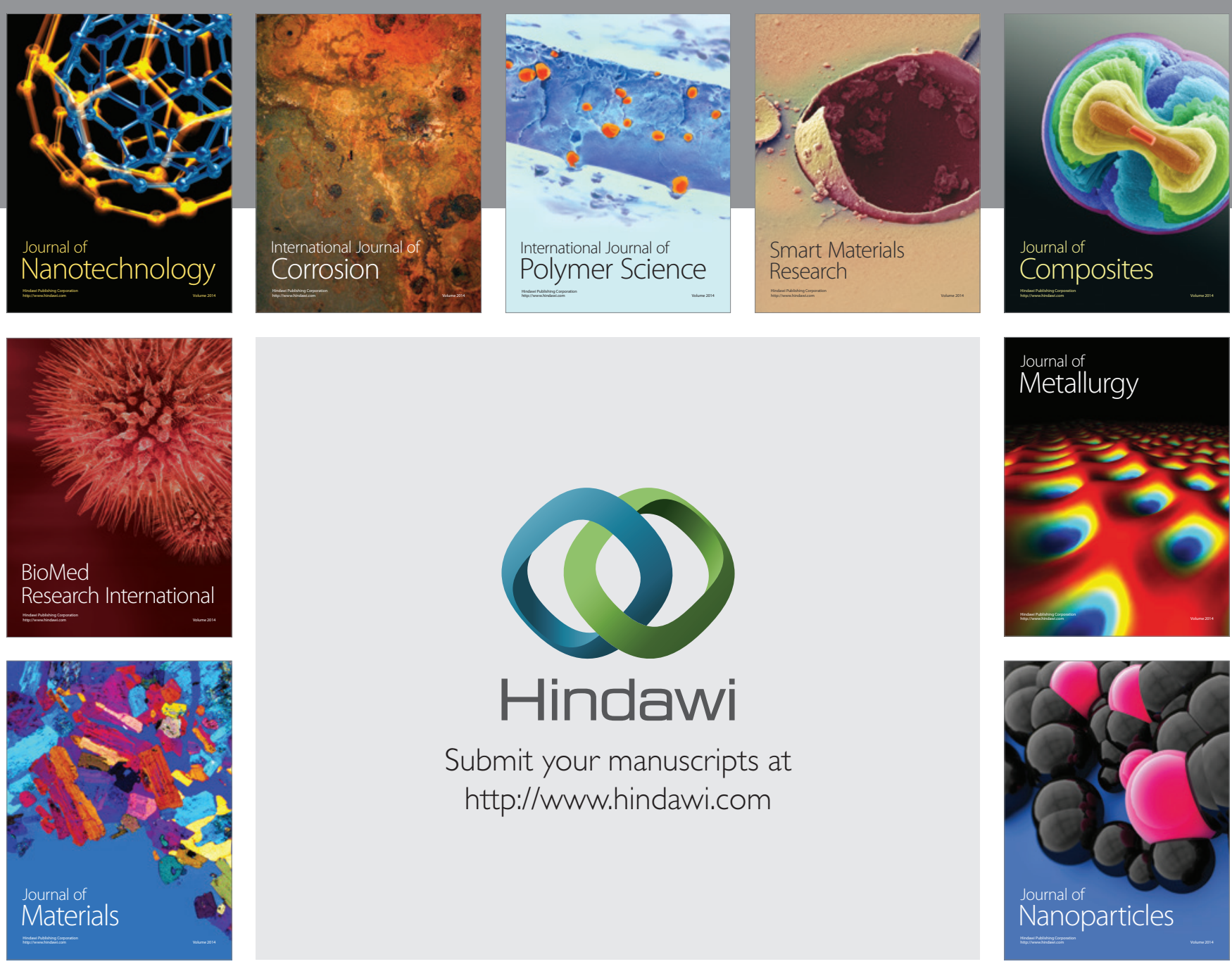

Submit your manuscripts at http://www.hindawi.com
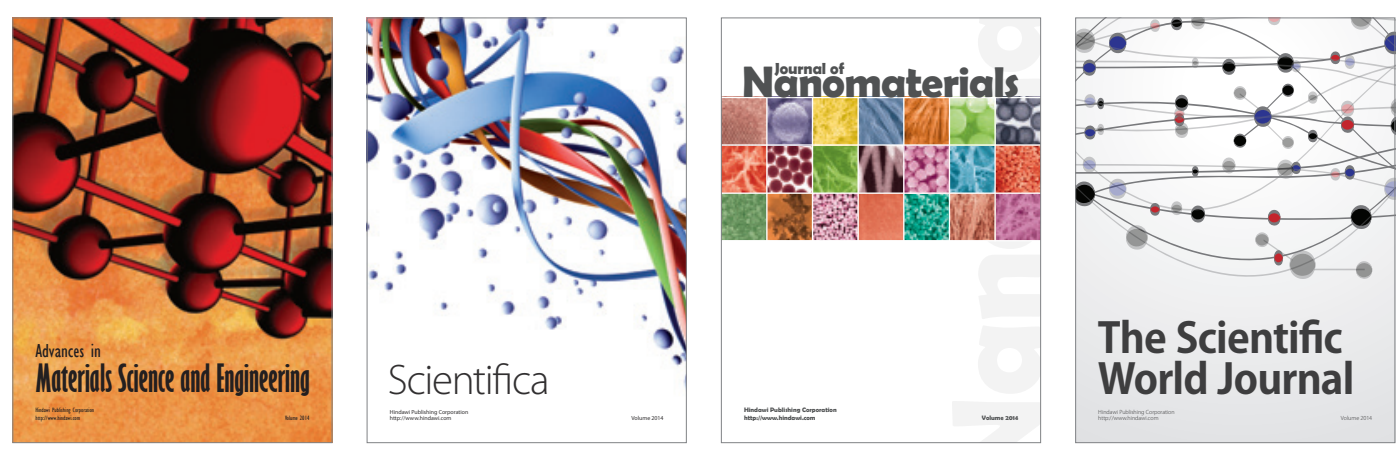

\section{The Scientific World Journal}
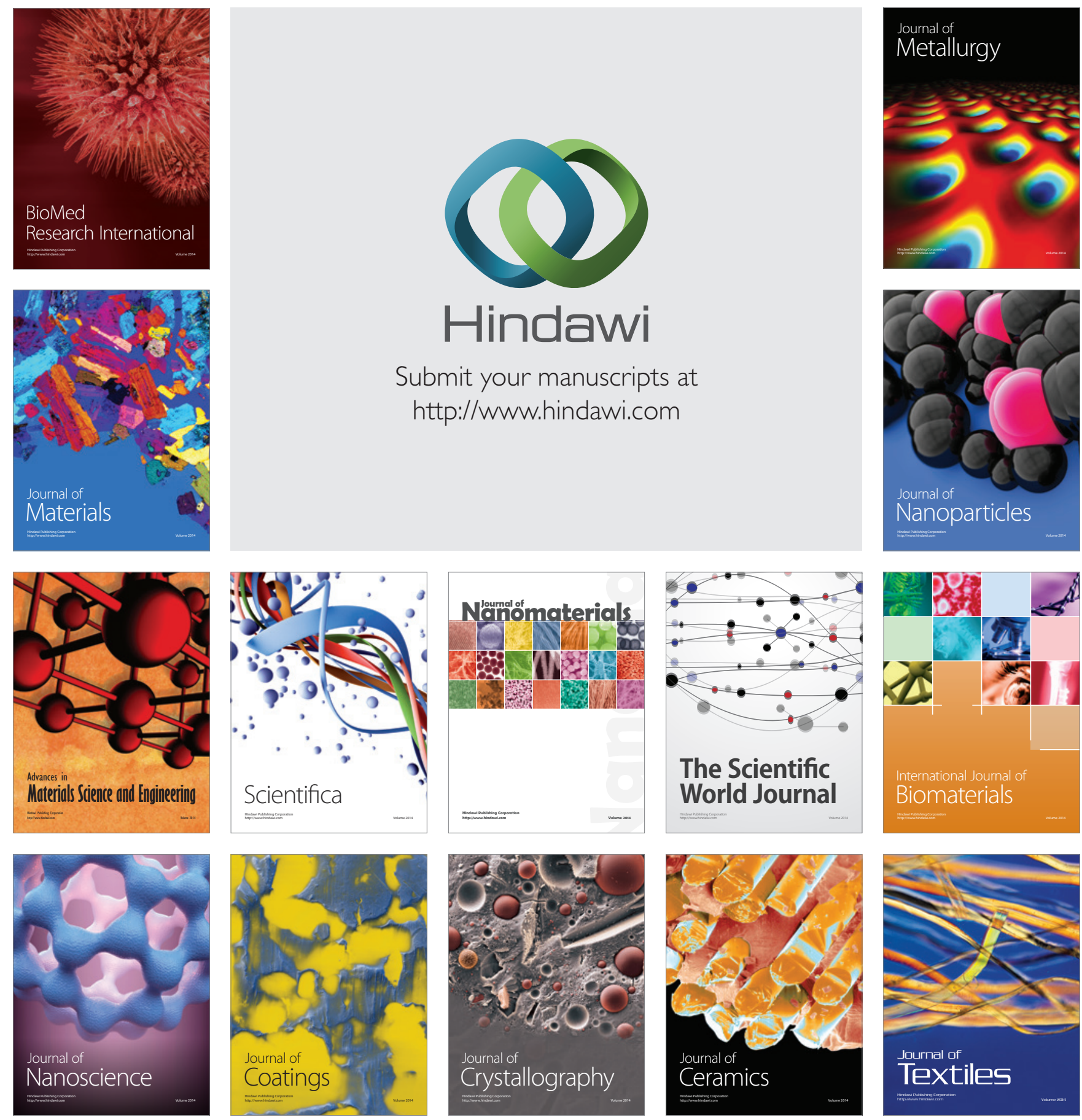